University of Nebraska - Lincoln

DigitalCommons@University of Nebraska - Lincoln

Development of Granular Boric Acid Sugar Baits for House Flies (Diptera: Muscidae)

Jerome A. Hogsette

USDA-ARS, Jerry.Hogsette@ars.usda.gov

David A. Carlson

USDA-ARS

Alyce S. Nejame

USDA-ARS

Follow this and additional works at: https://digitalcommons.unl.edu/usdaarsfacpub

Part of the Agricultural Science Commons

Hogsette, Jerome A.; Carlson, David A.; and Nejame, Alyce S., "Development of Granular Boric Acid Sugar Baits for House Flies (Diptera: Muscidae)" (2002). Publications from USDA-ARS / UNL Faculty. 1012. https://digitalcommons.unl.edu/usdaarsfacpub/1012

This Article is brought to you for free and open access by the U.S. Department of Agriculture: Agricultural Research Service, Lincoln, Nebraska at DigitalCommons@University of Nebraska - Lincoln. It has been accepted for inclusion in Publications from USDA-ARS / UNL Faculty by an authorized administrator of DigitalCommons@University of Nebraska - Lincoln. 


\title{
Development of Granular Boric Acid Sugar Baits for House Flies (Diptera: Muscidae)
}

\author{
JEROME A. HOGSETTE, ${ }^{1}$ DAVID A. CARLSON, AND ALYCE S. NEJAME \\ Center for Medical, Agricultural, and Veterinary Entomology, USDA-ARS, P.O. Box 14565, Gainesville, FL 32604
}

J. Econ. Entomol. 95(5): 1110-1112 (2002)

\begin{abstract}
Freeze-dried, granular sugar baits containing boric acid as the toxicant were evaluated against house flies, Musca domestica $\mathrm{L}$., in two bioassays with toxicant dose ranges of $3,5,7,8$, and $12 \%$, and $3,5,9,17$, and $33 \%$ boric acid, respectively, calculated and expressed on a dry weight basis. Flies in bioassay 1 were mixed sex and unstarved and flies in bioassay 2 were females only and starved $4 \mathrm{~h}$ before testing began. $\mathrm{LC}_{50} \mathrm{~s}$ were 8.97 and $14.33 \%$, and $\mathrm{LT}_{50} \mathrm{~s}$ were 59.75 and $53.34 \mathrm{~h}$ in bioassays 1 and 2 , respectively. Baits were tested at concentrations as high as $33 \%$, however there was no indication of repellency as seen previously with liquid baits. Reasons for lack of repellency and potential uses for baits are discussed. Development of efficacious granular baits would allow the presentation of higher levels of boric acid in volumes much smaller than required for liquid baits.
\end{abstract}

KEY WORDS house fly, Musca domestica, boric acid, granular baits, repellency

BORIC ACID CEASED to be used as a toxicant in house fly, Musca domestica L., baits after the appearance of the more efficacious and faster acting organophosphorus compounds in the early 1950s (Langford et al. 1954). However, in the search for environmentally friendly pesticides, there has been a renewed interest in boric acid as a toxicant to combat a number of peridomestic pest species (Hogsette and Koehler 1992; Strong et al. 1993; Klotz et al. 1994, 1996). Boric acid is a good candidate toxicant because is not classified as a carcinogen or skin irritant, and eye irritation, should it occur, is slight and reversible (Material Safety Data Sheets, U.S. Borax, Los Angeles, CA).

An important factor elucidated by recent research is the potential for borate baits to be repellent to target species at higher concentrations. With house flies this was true for boric acid and polybor liquid bait concentrations $>2.25$ and $3 \%$, respectively (Hogsette and Koehler 1994), and for polybor paste bait (made by drying a moistened mixture of borate and sugar) concentrations $>2 \%$ (Mullens and Rodriguez 1992). Besides the repellency factor restricting the upper limit of bait concentrations, baits in a liquid form may be difficult to use successfully in some urban settings and particularly in agricultural situations where dust could clog applicators and prevent contact with target species.

Therefore, the purpose of our study was to determine the efficacy of granular baits made by freeze

This article reports the results of research only. Mention of a proprietary product does not constitute an endorsement or a recommendation by USDA for its use.

${ }^{1}$ E-mail: jhogsette@gainesville.usda.ufl.edu. drying liquid formulations of boric acid and sugar. Preliminary data indicate a possible difference in toxicity and repellency levels to house flies when compared with liquid bait formulations. Such baits could be used much like commercially available granular fly baits and applied much easier than liquid formulations in many situations.

\section{Materials and Methods}

Test Insects. House flies from the USDA Gainesville multiresistant colony were used for all tests and basic rearing techniques were similar to those described by Hogsette (1992) unless otherwise stated. Adults were maintained in colony cages ( $46 \mathrm{~cm}$ long by $38 \mathrm{~cm}$ wide by $38 \mathrm{~cm}$ high), held under standard laboratory conditions $\left(26 \pm 2^{\circ} \mathrm{C}, 60 \pm 5 \% \mathrm{RH}\right.$, a photoperiod of $12: 12$ [L:D] h), and given ad libitum access to water and a dry adult diet consisting of powdered milk, granulated sugar, and powdered egg yolk (6:6:1) (Hogsette and Koehler 1992).

Bait Preparation. Baits were formulated in 10\% (wt: vol) aqueous sucrose solutions to which boric acid was added (wt:vol) in predetermined amounts. Solutions were heated slightly to facilitate the dissolving process. Sugar and boric acid were used in quantities sufficient to yield $\approx 10 \mathrm{~g}$ of formulated bait at each desired concentration after freeze drying was completed. A control bait was prepared from a $10 \%$ sucrose solution. Baits concentrations were formulated and expressed on a dry weight basis.

Liquid baits were freeze dried (Virtis Research Equipment, model 10-100, Gardiner, NY) in clean 500-ml polyethylene terephthalate drink bottles cut to 
Table 1. Response of house flies to freeze-dried granular sugar baits having boric acid as the toxicant

\begin{tabular}{|c|c|c|c|c|c|}
\hline House flies & $n$ & Slope $\pm \mathrm{SE}$ & Mortality statistic & Value & $95 \% \mathrm{CI}$ \\
\hline Unsexed, not starved $^{a}$ & 383 & $1.60 \pm 0.26$ & $\mathrm{LC}_{50}$ & $8.97 \%$ & $7.28-12.38$ \\
\hline Unsexed not starved & 281 & $5.25 \pm 0.56$ & $\mathrm{LT}_{50}$ & $59.75 \mathrm{~h}$ & $54.77-64.73$ \\
\hline Females only, starved $4 \mathrm{~h}^{b}$ & 664 & $0.84 \pm 0.19$ & $\mathrm{LC}_{50}$ & $14.33 \%$ & $7.76-55.73$ \\
\hline Females only, starved $4 \mathrm{~h}$ & 162 & $7.15 \pm 0.74$ & $\mathrm{LT}_{50}$ & $53.34 \mathrm{~h}$ & $49.61-56.89$ \\
\hline
\end{tabular}

${ }^{a}$ Bioassay 1.

${ }^{b}$ Bioassay 2.

fit when inserted inside 400-ml round-bottom freeze drying flasks. After liquid bait formulations were prepared, they were transferred to individual polyethylene terephthalate inserts and frozen while swirling in a dry ice and ethanol slurry. Swirling ensured that baits would freeze in thin layers on the walls of the inserts, thus producing a large surface area that would facilitate freeze drying. When a bait solution was completely frozen, the insert was slipped immediately into a freeze-drying flask, attached to the freeze dryer, and processed at $-50^{\circ} \mathrm{C}$ and $10-20 \mathrm{mmHg}$ for $24-48 \mathrm{~h}$. The dry crystalline baits were removed from the inserts with a metal spatula, and broken into granules of random sizes in the process. Granules were transferred to clean $20-\mathrm{ml}$ scintillation vials, labeled, and stored inside a dessicator over anhydrous calcium sulfate.

Bioassays. Two bioassays were performed. Being concerned about the potential for borate repellency as shown in previous studies (Mullens and Rodriguez 1992, Hogsette and Koehler 1994), liquid bait concentrations in bioassay 1 were restricted to $3,5,7,8$, and $12 \%$ boric acid. Unstarved, mixed-sex 3- to 5-d-old house flies were tested in bioassay 1 . In the second bioassay, bait concentrations of $3,5,9,17$, and $33 \%$ boric acid were formulated to include levels that exceeded the $12 \%$ level of bioassay 1 . In bioassay $2,3-$ to 5-d-old female house flies starved (no food, but water access) for $4 \mathrm{~h}$ were used for testing. There was no indication that mortality in previous boric acid studies was related to sex, but using only female flies eliminated any possibility of sex-related bias. Flies in bioassay 2 were starved to increase feeding activity, which was expected to produce a faster rate of kill. Other procedures were essentially the same for both bioassays. Flies were anesthetized with $\mathrm{CO}_{2}$ for $<10$ min, sorted, placed in small $(\approx 3.4 \mathrm{~cm}$ high and $7.6 \mathrm{~cm}$ diameter) disposable test cages (25 per cage) (Hogsette and Koehler 1992), and allowed to recover for $\approx 30 \mathrm{~min}$ before each test began.

For each bioassay, five colony cages (described above) were furnished with $1 \mathrm{~g}$ of each bait concentration contained in an aluminum weigh boat $(1 \mathrm{~cm}$ high and $5 \mathrm{~cm}$ diameter). A sixth cage with $1 \mathrm{~g}$ of freeze-dried sugar in the same size weigh boat served as a positive control. A seventh cage furnished only with water served as a negative control. Water was provided in all cages ad libitum in 150-ml beakers with polyfoam chips covering the surface to minimize fly mortality from drowning (Hogsette 1992). Flies were released from the disposable test cages into each col- ony cage with the bait and water, and mortality counts were made at $24,48,72$, and 96 h thereafter. Criterion for death was complete cessation of movement.

Statistical Analysis. Each bioassay was performed four times and pooled data were subjected to probit analysis (SAS Institute 1985) for estimation of $\mathrm{LC}_{50} \mathrm{~S}$ and $\mathrm{LT}_{50} \mathrm{~S} . \mathrm{LC}_{50} \mathrm{~s}$ were estimated from 72-h mortality data because this is when mortality was observed in all bait concentrations. The 12 and $17 \%$ boric acid baits were used in a destructive sampling design to collect data for estimating $\mathrm{LT}_{50}$ values in bioassays 1 and 2, respectively.

\section{Results and Discussion}

In bioassay 1 , the $\mathrm{LC}_{50}$ after 72-h exposure of unsexed and unstarved house flies to freeze dried boric acid sugar baits was $8.97 \%$ and the $\mathrm{LT}_{50}$ at the $12 \%$ concentration was $59.75 \mathrm{~h}$ (Table 1 ). In bioassay 2 , the $\mathrm{LC}_{50}$ after 72-h exposure of starved female house flies was $14.33 \%$ and the $\mathrm{LT}_{50}$ at the $17 \%$ concentration was $53.34 \mathrm{~h}$ (Table 1).

$\mathrm{LC}_{50} \mathrm{~s}$ in our bioassays exceeded the $\mathrm{LC}_{50}$ of $0.88 \%$ found in earlier trials by Hogsette and Koehler (1992) for liquid boric acid baits formulated in $10 \%$ sucrose. This could be a result of differential rates of feeding by flies on liquids and solids. House flies exposed a 2.25\% liquid boric acid bait formulated in $10 \%$ sucrose consumed $0.583 \mathrm{mg}$ of active ingredient in $9 \mathrm{~h}$ (Hogsette and Koehler 1994). A freeze-dried version of the same bait provides the potential for a similar or higher boric acid intake. However, sufficient water must be imbibed separately and this may affect borate internal processing in the fly. House flies exposed to liquid boric acid baits formulated in $10 \%$ sucrose were repelled by concentrations $>2.25 \%$ and thus imbibed less bait solution (Hogsette and Koehler 1994). The freeze dried baits may have caused an undetected reduction in fly feeding, but flies exposed to all bait concentrations died slower than flies provided only with water in the negative control. The flies visited and appeared to be feeding on baits to which they were exposed. Boric acid acts as a stomach poison in house fly adults (Marcovitch and Anthony 1931) and there is no reason to suspect that adsorption might be an added cause of mortality.

The most important and interesting result of our study is that the $\mathrm{LC}_{50} \mathrm{~s}$ greatly exceed the levels of $2-3 \%$ polybor and $2.25 \%$ boric acid found previously to be repellent to house flies (Mullens and Rodriguez 1992, Hogsette and Koehler 1994). The 33\% freeze- 
dried bait contains a ten-fold increase in boric acid on a dry weight basis. The lack of repellency observed with the freeze-dried boric acid baits was completely unexpected and reasons for its manifestation are not understood. Some unidentified factor, possibly a contaminant that makes certain concentrations of liquid and paste baits repellent to the flies, may be volatilized and lost during the freeze-drying process. Perhaps there is a structural change as a result of freeze drying that renders the boric acid more acceptable to the flies. Mullens and Rodriguez (1992) also dried their baits, but in an oven, and repellency persisted in concentrations $>2 \%$. Additional studies are needed to clarify this phenomenon.

The fact that the flies are not repelled by any of the freeze-dried baits presents the possibility of delivering more toxicant to the flies in a smaller volume, i.e., a granular compared with a liquid formulation. The solubility of boric acid is only $4.72 \%$ in water (Hogsette and Koehler 1992), which limits the amount that can be dispensed in a liquid form even if repellency were not a problem. $\mathrm{LT}_{50}$ estimates for bioassays 1 and 2 differed by only $6 \mathrm{~h}$ although the calculations were made with mortality values from the 12 and $17 \%$ baits, respectively. Starved flies died faster, but the bait concentration was higher as well (Table 1 ). $\mathrm{LT}_{50}$ values in both bioassays exceeded by $2.5 \times$ the $\mathrm{LT}_{50}$ reported by Hogsette and Koehler (1992) for 0.5\% boric acid formulated in $10 \%$ sucrose, indicating a much slower kill with the freeze-dried granular baits at much higher boric acid concentrations.

In summary, freeze-dried granular boric acid baits appear to have a slower rate of kill at higher concentrations than liquid boric acid formulations. However, repellency was not observed in any of the granular bait concentrations we evaluated. A slower rate of kill was once regarded as a negative attribute, but this is not necessarily the case at this writing. An environmentally safe bait that begins to produce high levels of mortality after $48 \mathrm{~h}$ may be a suitable alternative to more toxic baits, especially those with reduced efficacy resulting from pesticide resistance. Although it was out of the scope of this research, using granular baits with boric acid concentrations $>2 \%$ may increase the frequency of the reproductive disorders observed by Mullens and Rodriguez (1992). This would make the granular baits more attractive for use, despite the observed slower rate of kill. Before field testing can be accomplished, more research is needed to determine whether the efficacy of the freeze-dried granular boric acid baits can be improved.

\section{Acknowledgments}

We are very grateful to Mandy Falkner (USDA-ARS, Gainesville) for her invaluable help in the laboratory studies. A.S.N. performed these studies as partial fulfillment of her requirements for competing and subsequently winning fourth place in Senior Zoology in the 2002 Florida State Science and Engineering Fair.

\section{References Cited}

Hogsette, J. A. 1992. New diets for production of house flies and stable flies (Diptera: Muscidae) in the laboratory. J. Econ. Entomol. 85: 2291-2294.

Hogsette, J. A., and P. G. Koehler. 1992. Comparative toxicity of aqueous solutions of boric acid and polybor 3 to house flies (Diptera: Muscidae). J. Econ. Entomol. 85: 1209-1212.

Hogsette, J. A., and P. G. Koehler. 1994. Repellency of aqueous solutions of boric acid and polybor 3 to house flies (Diptera: Muscidae). J. Econ. Entomol. 87: 1033-1037.

Klotz, J. H., J. I. Moss, R. Zhao, L. R. Davis, Jr., and R. S. Patterson. 1994. Oral toxicity of boric acid and other boron compounds to immature cat fleas (Siphonaptera: Pulicidae). J. Econ. Entomol. 87: 1534-1536.

Klotz, J. H., D. H. Oi, K. M. Vail, and D. F. Williams. 1996. Laboratory evaluation of a boric acid liquid bait on colonies of Tapinoma melanocephalum Argentine ants and Pharaoh ants (Hymenoptera: Formicidae). J. Econ. Entomol. 89: 673-677.

Langford, G. S., W. T. Johnson, and W. C. Harding. 1954 Bait studies for fly control. J. Econ. Entomol. 47: 438 - 441.

Marcovitch, S., and M. V. Anthony. 1931. A preliminary report on the effectiveness of sodium fluosilicate as compared with borax in controlling the house fly (Musca domestica Linne). J. Econ. Entomol. 24: 490-497.

Mullens, B. A., and J. L. Rodriguez. 1992. Effects of disodium octaborate tetrahydrate on survival, behavior, and egg viability of adult muscoid flies (Diptera: Muscidae). J. Econ. Entomol. 85: 137-143.

Strong, C. A., P. G. Koehler, and R. S. Patterson. 1993. Oral toxicity and repellency of borates to German cockroaches (Dictyoptera: Blatellidae). J. Econ. Entomol. 86: 14581463.

SAS Institute. 1985. SAS user's guide: statistics. SAS Institute, Cary, NC.

Received for publication 22 January 2002; accepted 26 March 2002. 